\title{
PASANG SURUT PENYEBARAN AGAMA KATOLIK DI MALUKU UTARA PADA ABAD 16-17
}

\author{
The Rise and Down of Catholicism in the Northern Moluccas \\ in the $16^{\text {th }}-17^{\text {th }}$ Century
}

Cheviano E. Alputila

Balai Arkeologi Ambon

J1. Namalatu-Latuhalat Kota Ambon 97118

Email: kelkyvoor@yahoo.com

Naskah diterima: 24-01-2014; direvisi: 02-04-2014; disetujui: 09-05-2014

\begin{abstract}
Until the 18th century the spice is a tremendous appeal to the international community. No exception with cloves then just grow on some island in the North Moluccas. Two first nation to get a clove monopoly rights in North Maluku is Portuguese and Spanish. When activity in the region is not only the two nations trade, but also spread their religion is Catholicism. Through a review of the literature from a variety of sources, the conclusion about the spread of the Catholic faith that made the Portuguese and Spanish in their efforts to monopolize the clove trade in North Moluccas. In the end, the spread of Catholicism that made the Portuguese and Spanish only reinforce hatred against their local authorities and result in the expulsion of both these imperialist nations of North Moluccas.
\end{abstract}

Keywords: Catholic, North Moluccas, Spices

\begin{abstract}
Abstrak
Sampai abad ke-18 rempah-rempah merupakan daya tarik yang luar biasa bagi masyarakat internasional. Tidak terkecuali dengan cengkeh yang saat itu hanya tumbuh pada beberapa pulau di kawasan Maluku Utara. Dua bangsa pertama yang mendapatkan hak monopoli cengkeh di Maluku Utara adalah Portugis dan Spanyol. Saat beraktivitas di kawasan itu dua bangsa ini tidak hanya berdagang namun juga menyebarkan agama yang mereka anut yaitu Kristen Katolik. Melalui telaah pustaka dari berbagai sumber, diperoleh kesimpulan tentang penyebaran agama Katolik yang dilakukan Portugis dan Spanyol di tengah usaha mereka memonopoli perdagangan cengkeh di Maluku Utara. Pada akhirnya, penyebaran agama Katolik yang dilakukan Portugis dan Spanyol hanya memperkuat kebencian para penguasa lokal terhadap mereka dan berakibat terusirnya kedua bangsa imperialis ini dari Maluku Utara.
\end{abstract}

Kata Kunci: Katolik, Maluku Utara, Rempah-Rempah

\section{PENDAHULUAN}

Katolik Roma adalah salah satu agama terbesar di dunia. Ada kurang lebih 1,86 miliar orang penduduk dunia yang secara resmi memeluk agama ini. Berdasarkan hasil survei Badan Pusat Statistik tahun 2010, wilayah dengan penduduk Katolik terbanyak di Indonesia antara lain terdapat di Propinsi Nusa Tenggara Timur, Kalimantan Barat, Papua, dan Jawa Tengah (www.bps.go.id,
2010). Dewasa ini meskipun mayoritas penduduk Propinsi Maluku Utara beragama Islam ${ }^{1}$, ajaran Katolik pada abad ke-16-17 sempat tertanam kuat di sana dan menjadi salah satu tempat dengan populasi umat

\footnotetext{
1. Penduduk yang beragama Islam di Propinsi Maluku Utara berdasarkan hasil sensus penduduk yang dilakukan Badan Pusat Statistik Nasional berjumlah 777.110 jiwa atau 74,3 persen dari total 1.038.087 jiwa. Sedangkan penduduk yang beragama Kristen Katolik berjumlah 5.378 atau 0,52 persen (www.bps.go.id, 2010).
} 
terbanyak di Asia. Pada masa itu Katolik yang masuk di Maluku Utara dibawa oleh bangsa Portugis dan kemudian disusu oleh Spanyol. Khusus bagi Portugis, yang lebih disorot dalam tulisan ini, terdapat dua alasan untuk menjelaskan kemajuan merek dibidang pelayaran. Pertama, ekspansi bangsa Lusitania ini didukung oleh pemimpinny saat itu yaitu Raja Henry 'Si Pelaut' (1394 1460 M) yang mendorong pelaut-pelaut Portugis untuk melakukan penemuan daerah baru. Kedua adalah pengejaran terhadap orang-orang moor (Islam) pasca perang salib. Kebencian terhadap Islam semakin diperparah karena bangsa Portugis dan Spanyol sempa dijajah lima abad lamanya (700-1250 M) oleh bangsa pengembara dari Afrika Utara yang kebetulan beragama Islam (Andaya, 1993:123). Untuk mewujudkan hal tersebut Raja Henry berusaha untuk mengembangkan perdagangan Portugis dengan cara menguasa perdagangan rempah-rempah (Amal, 2010b:3 4 dan Alwi, 2005:310).

Pada abad pertengahan hingga akhi abad ke-18 rempah-rempah merupakan komoditas yang paling dicari. Rempahrempah menjadi sangat penting di Eropa karena berbagai kegunaan yang dimilikinya. Pada musim dingin dimana daging sega susah didapatkan karena ketiadaan pakan untuk ternak, solusi terbaik adalah dengan mengawetkan daging dengan menggunakan garam. Untuk menghilangkan rasa asi dan bau tengik dari daging yang mulai membusuk maka digunakanlah rempahrempah untuk menyamarkannya. Selain berfungsi memberi rasa pada ikan atau daging yang diawetkan rempah dipercaya sebaga peningkat gairah seksual, obat berbaga penyakit serta dimanfaatkan sebagai bahan kosmetik (Turner, 2011:198-199).

Mengapa Portugis dan Spanyol mau bersusah payah menguasai perdagangan pala dan cengkeh? Jawaban dari pertanyaan ini tak lain karena keuntungan yang sanga menjanjikan jika memperdagangkan komodit tersebut. Portugis menjuluki cengkeh dan pala dengan sebutan 'buah emas'. Saking mahalnya mereka menganggap cengkeh dan pala dapat disetarakan dengan emas hitam (budak) dari Kongo atau bahkan emas asli dar suku Aztec dan Inca. Sekedar perbandingan, di Maluku pada tahun 1600-an setengah kilogram cengkeh dibeli dengan harga setengah penny ( 100 penny $=1$ poundsterling mata uang Inggris), sedangkan di pasar Eropa harganya bisa mencapai 16 poundsterling. Jadi jika dihitung-hitung keuntungan setiap menjual setengah kilogram cengkeh adala 32.000 persen. 32.000 persen. (Ashley Abbas dalam Amal 2010b:357). Tak heran Portugis dan Spanyo menghalalkan segala cara demi menguasa perdagangan komoditi tersebu di Maluku Utara.

Selain berusaha untuk menguasa perdagangan rempah-rempah, setiap gubernur Portugis yang bertugas di Maluku memiliki tugas lain yaitu menyebarkan Katolik kepada siapapun yang ditemui. Hubungan kerajaan Portugis dan Spanyol dengan agama Katolik pada abad pertengahan lazim disebut padroado. Agama menguasa seluruh sendi kehidupan masyarakat sehingga Gereja Katolik sebagai lembaga pengayom berada di atas pemerintahen yang berkuasa. berada di atas pemerintahan Dengan kata lain kerajaan sebagai abdi dari gereja wajib melindungi agama Katolik dari ancaman-ancaman dan mendukung penyiarannya sampai keluar negara (Van Den End dan Weitjens, 2001:22-27). Padahal saat Portugis ingin menjalin hubungan dengan Ternate, mayoritas masyarakat Maluku Utara telah (sslam selama lebih dari setengah abad lamanya. Kerajaankerajaan besar di wilayah ini yaitu Ternate ,Tidore, Bacan, dan Jailolo telah menerim Islam dan menjadikannya sebagai agama kerajaan sehingga penyebaran Katolik yang dilakukan Portugis dan Spanyol nantinya akan menimbulkan pertentangan oleh penguasapenguasa wilayah tersebut. Dengan kata lain pilihan menjadi Katolik adalah pilihan politik melawan kedaulatan para sultan Muslim (Boelaars, 2009:59 dan Aritonang, 2006:15) Selama ini kajian yang secara khusus membahas tentang penyebaran agama Katolik di Maluku Utara pada abad 16-17 masih minim. Beberapa penulis yang secara mendalam pernah menyajikan topik ini dalam karya mereka antara lain adalah Adnan Amal serta Böhm dan pengemanan. Tulisan ini dibuat dengan harapan melengkapi kajian dibuat dengan harapan
tentang topik tersebut.

Dari penjabaran di atas maka permasalahan yang akan dijawab dalam tulisan ini adalah Bagaimanakah penyebaran agama Katolik yang dilakukan bangsa Portugis dan Spanyol di Maluku Utara?

\section{METODE}

Tulisan ini bertujuan untuk mengetahui gambaran penginjilan yang dilakukan oleh orang-orang Portugis dan Spanyol di Maluku Utara berbarengan dengan usaha mereka untuk memonopoli perdagangan rempahrempah. Pada masa ini penyebaran Katolik juga dilakukan oleh bangsa Spanyol namun tidak seintens yang dilakukan oleh Portugis sehingga tulisan ini lebih memfokuskan pada penyebaran Katolik yang dilakukan oleh Portugis. Adapun pembatasan penulisan hanya membahas pada penyebaran agama Katolik pada abad 16 dan 17 karena hubungan bangsa Portugis-Spanyol dengan Maluku dimulai pada 1512 dan berakhir tahun 1663 saat armada Spanyol meninggalkan Tidore. Oleh karena itu, metode yang digunakan dalam penelitian ini adalah studi pustaka untuk memperoleh data mengenai sejarah penyebaran katolik. Selanjutnya, digunakan metode analisis deskriptif untuk menjawab permasalahan penelitian.

\section{HASIL DAN PEMBAHASAN}

\section{Keadaan Maluku Utara Sebelum}

\section{Kedatangan Portugis dan Spanyol}

Saat Portugis dan Spanyol berusaha

untuk menyebarkan Katolik di Maluku Utara sudah ada kepercayaan lain yang telah eksis sebelumnya. Agama Islam adalah salah satunya. Sejauh ini para ahli belum bisa menentukan secara akurat sejak kapan salah satu agama samawi ini telah dipeluk oleh kerajaan-kerajaan disana. Namun berdasarkan sumber-sumber Portugis, Islam dapat diperkirakan telah ada sekurangkurangnya pada 1486 sejak Zainal Abidin di Ternate menggunakan gelar sultan saat ia dilantik menjadi raja (Amal, 2010a: 236,241). Gelar tradisonal penguasa wilayah Ternate dan daerah lain di Maluku Utara adalah kolano.

Pada akhir abad ke-15 sampai awa abad ke-16 ajaran Islam mulai melembagaka diri dalam pemerintahan raja-raja penguasa Maluku Utara. Di ternate hal ini dimula pada masa pemerintahan Raja Zainal Abidin dan diperkuat dengan kebijakan penerusnya yaitu Bayanullah. Abidin membentuk institusi baru dalam kerajaan yang disebut dengan bobato akhirat. Tugasnya antara lain memelihara kehidupan rohani masyaraka dengan mengadakan ritual-ritual Islami. Bobato akhirat atau jolebe ini juga berfungsi sebagai hakim khusus di bidang hukum kekeluargaan dan hukum waris islam. Tidak sampai disitu saja, pengangkatan seluruh bobato dunia (pejabat kerajaan) dan jabatan lainnya wajib dijabat oleh seorang muslim. Hal penting lainnya adalah dibangun sejumlah sekolah dengan guru-guru ulama yang berasal dari Giri (Jawa Timur); tempat

Meskipun Islam telah mengakar ku di hampir seluruh wilayah Maluku Utara, ada daerah-daerah tertentu yang masih menjalankan kepercayaan asli pra-Islam. Umumnya pemeluk Islam di Maluku Utara menetap di pesisir pantai sehingga daerah pedalaman atau yang sulit dijangkau pada masa itu masih meneruskan tradisi animismedinamisme. Salah satu wilayah yang masih menganut kepercayaan kuno ini adalah penduduk di Moro (Abdurrachman, 2008:127) Salah satu elemen penting dalam kepercayaan kuno ini adalah pemujaan terhadap leluhur Bentuk seperti ini merupakan kelanjutan radisi yang dipelihara sejak jaman prasejarah. Penganutnya percaya bahwa objek di angkasa eperti matahari bulan dan bintang merupakan tempat kediaman para dewa. Sedangkan roh jahat dipercaya mendiami pohon-pohon, gunung dan goa. Pemujaan terhadap leluhu dan dewa-dewa biasanya dilakukan di tempat yang dikeramatkan seperti di depan batu meja (dolmen). Pemimpin upacara menjadi tokoh 
yang sangat penting karena berfungsi sebagai "penyambung lidah" dari dewa atau leluhur. Setiap peristiwa yang terjadi di luar kelaziman akan langsung dikaitkan dengan kepercayaan mereka. Masyarakat sangat percaya denga kekuatan supranatural yang ada di sekita mereka. Hal ini dapat dibuktikan dengan sesajen yang diletakkan di tempat-tempa mereka beraktivitas. Masyarakat juga sangat percaya dan takut kepada roh-roh jahat yang dipercaya dapat menggange kehidupan manusia (Rijoly, 1977:237, Leirisa, 1999:912 dan Böhm dan Pangemanan, 2012:53)

Dari segi politik, sebelum kedatangan Portugis dan Spanyol wilayah Maluku Utar sudah dikuasai oleh penguasa-penguasa loka dalam bentuk kesultanan Islam. Mereka adalah Bacan, Jailolo Ternate dan Tidore. Keempat kerajaan tersebut saling bersaing untuk berusaha menjadi penguasa tunggal $\mathrm{di}$ daerah ini.

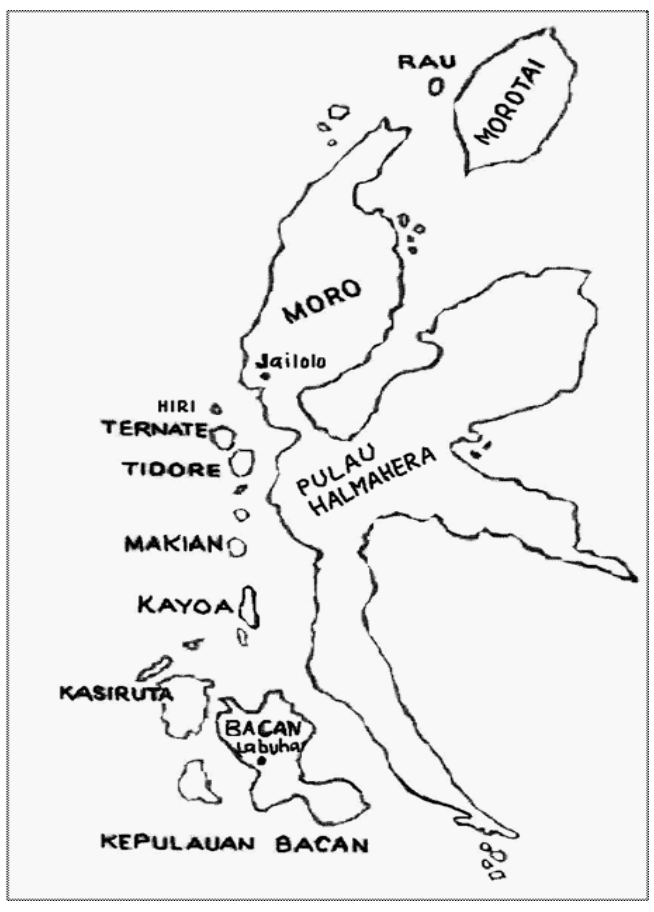

Gambar 1: Peta Halmahera da

Pulau-Pulau di Sekitarnya

(Sumber: Böhm dan Pangemanan, 2010: 76)

Sejak kapan permusuhan ini dimula tidak dapat diketahui dengan pasti. Namu dari keempat nama tersebut Ternate dan Tidore merupakan kerajaan yang persaingannya sangat nampak. Bentuk persaingan ini terlihat saat pasukan Portugis yang dipimpin Serrao datang ke Maluku Tengah dan membantu Hitu menghalau tentara dari Pulau Seram pada tahun 1512. Keahlian pasukan Serrao dalam berperang dengan menggunakan halhal yang baru seperti senjata, baju pelindung dan meriam membuat Ternate dan tidore langsung mengirim juanga untuk menjemput Serrao dan anak buahnya. Keunggulan Ternate yang berhasil mendatangkan Portugis untuk bekerjasama tidak selamanya berjalan mulus karena pada 1521 Tidore berhasil menjalin kemitraan dengan Spanyol yang juga merupakan musuh Portugis. Adapun kerajaan yang lebih kecil seperti Moro, Obi, memiliki kekuasaan besa dan belakangan punah karena dianeksasi oleh keraan-kerajaan diatas.

Keadaan Maluku Utara Saat Berlangsungnya Penyebaran Katolik

Agama Katolik di Maluku Utara disebarkan oleh para imam laki-laki yang dikenal dengan sebutan pastor. Sebelum para pastor atau misonaris ini datang ke Maluku Utara mereka memperoleh pendidikan layaknya orang yang berkuliah di universitas. Sekolah tempat mereka menuntut ilmu Beberapa ordo yang mengirimkan para pastornya untuk menyebarkan Katolik di Maluku Utara pada abad 16 dan 17 antara lain Fransiskan, Dominikan, Agustin, dan Serikat Yesus. Nama terakhir yang disebutkan diatas nantinya akan menghasilkan salah satu penyebar ajaran Katolik yang sangat mahsyur di Asia. Misionaris ini adalah Fransiskus Xaverius (1506-1552). Sebagai penghormatan atas jasa-jasanya nama Xaverius diabadikan menjadi nama gereja pusat Katolik Propinsi Maluku di kota Ambon.

Sebenarnya cikal bakal penyebaran Katolik bagi penduduk Maluku Utara adalah pelayanan rohani yang diberikan bagi para serdadu dan penumpang selama pelayaran. Di setiap kapal Portugis dan Spanyol yang berlayar minimal disediakan seorang pasto untuk menjawab kebutuhan rohani para awak kapal. Pelayanan kerohanian menjadi semakin ang Portugis mulai mendirikan benteng dan loji dagang. Pelayanan rohani pertama kali di dalam benteng diberikan tahun 1522 setelah benteng Sao Paolo atau Gamlamo dibangun di Ternate. Sao Paolo atau Gamlamo merupakan benteng pertama yang berhasil dibangun Portugis di wilayah nusantara ${ }^{2}$. Secara tidak langsung keberadaan Spanyol pada 1521 di Tidore membuat sultan Ternate merasa perlu untuk menjalin sebuah kemitraan yang lebih erat dengan Portugis. Ternate kemudian berusaha mengambil hati Portugis dengan memberikan monopoli cengkeh serta ijin pembangunan benteng Sebelum tahun 1534 konversi masyarakat ke Katolik terjadi dengan sangat lambat. Sempat ada rombongan pastor yang datang pada 1523 namun tidak banyak sumber arsip yang berbicara tentang sepak terjang mereka. Para gubernur pada masa awal keberadaan portugis di Maluku Utara pun lebih fokus untuk mengatur perdagangan cengkeh sehingga penyebaran katolik saat itu tidak segiat masa-masa selanjutnya.

a. Penyebaran Katolik di Moro Saat Tristao de Atayde (1534-1537) menjabat sebagai gubernur ke-6 Portugis di Ternate barulah penyebaran Katolik di Ternate barulah penyebaran Katolik
mulai menggeliat. Saat datang ke Ternate ia membawa serta seorang pastor yaitu Simon Vaz. Penyebaran Katolik pertama kali dilakukan Vaz saat mengkonversi Raja Moro (pantai timur Halmahera Utara), bernama Tioliza, yang menganut kepercayaan animisme-dinamisme. Rupanya penyebab Tioliza bersedia untuk masuk Katolik yaitu agar diberi perlindungan Portugis atas serangan Kesultanan Jailolo dan Ternate yang ingin menganeksasi kawasan ini. Wilayah Moro pada saat itu merupakan penyuplai makanan seperti daging, ikan, sagu dan beras bagi pulau-pulau di sekitarnya sehingga merupakan daerah rebutan kerajaan-kerajaan 2 Nama asli benteng ini adalah Nostra Senhora del Rodisamakan sesuai dengan nama daerah dan istana raja yaitu Gamalamo atau Gamlamo (Djafaar, 2006:115). tetangganya (Amal, 2010a: 214)

Setelah mengajak petinggi kerajaan untuk dikonversi menjadi Katolik, Toaliza kemudian memproklamirkan bahwa Moro merupakan kerajaan Katolik. Ia mengundang Vaz untuk membaptis banyak orang di Mamuya dan Tolo. Di masing-masing wilayah ini sampai tahun 1535 telah dibangun dua gereja. Penginjilan di wilayah kerajaan Moro berjalan sukses antara lain karena didukung oleh Sultan Ternate Khairun Jamil yang naik takhta pada tahun yang sama. Khairu menginginkan Moro menjadi salah satu vaza Kesultanan Ternate sehingga ia berusah berusaha mengambil hati Portugis dengan membantu pekerjaan para pastor disana. Suatu ketika Khairun bahkan mengirimkan sebuah kapal yang berisi 400 pasukan untuk memusnahkan perusuh yang mengganggu kerja para pastor di Moro.

Akibatnya konversi masyarakat Moro ke Katolik terjadi dalam jumlah yang sangat besar. Pada tahun 1546 hampir seluruh wilayah Kerajaan Moro berhasil di-Kristenkan. Ada 18 desa di Morotai, 3 di Pulau Rau, dan 8 desa di wilayah Morotia (Pulau Halmahera) yang sudah menganut Katolik (Böhm dan Pangemanan, 2010. 34). Sampai dengan tahun 1553 penduduk yang berhasil dikonversi menjadi Katolik di Kerajaan Moro diperkirakan telah ada sebanyak 35.000 orang (Amal, 2010a: 220). Tolo yang merupakan pusat Katolik di Moroti bahkan dilengkapi dengan serdadu Portugis. Perkembangan Katolik yang tumbuh dengan sangat cepat dan sifat sewenang-wenang dari penguasa Portugis yang terlalu ikut campur dalam pelaksanaan kerajaan-kerajaan di Maluku Utara membuat Khairun berpikir ia harus secepatnya mengusir Katolik dan Portugis secepat mungkin. Pada 1553 Khairun mengadakan rapat rahasia yang dihadir oleh para sultan penguasa wilayah Maluku Utara. Dalam rapat itu diputuskan bahwa Portugis beserta produk Katoliknya haru diusir dari wilayah ini. Katarabumi yang pengangkatannya dibantu oleh gubernur Portugis diserahi tugas untuk memimpin 
pemusnahan penduduk Katolik di Moro sedangkan segi politik akan dipimpin oleh Khairun.

Katarabumi memulai perang dengan menghancurkan desa-desa di Morotia (Halmahera) kemudian berlanjut ke Pulau Morotai. Penduduk yang sebelumnya Katolik dimurtadkan sedangkan sisanya dibunuh Di Cawa (Chawa), sebuah daerah dekat Tolo, para penduduk yang telah murtad bahkan membakar gereja dan semua benda yang berhubungan dengan ajaran Katolik. Saat memasuki wilayah Tolo tentara Jailolo mendapat perlawanan hebat namun dalam waktu satu bulan daerah itu akhirnya bis dikuasai. Para penduduk yang berhasil lar dari wilayah ini kemudian berhasil sampai di Ternate dan melaporkan hal tersebut pada gubernur. Portugis kemudian mengambil tindakan dengan menyerang Jailolo. Pihak Ternate yang sebelumnya tidak menyetuju hal ini kemudian berhasil dipaksa Gubernu Bernaldyn de Sousa untuk ikut menyerang dan mengalahkan Jailolo. Penyebaran katolik di misi Katolik pun berjalan seperti sedia kal saat pemerintahan Jailolo dibawah Katarabum berhasil dilengserkan. Belakangan Ternate bahkan menjadikan kesultanan ini sebagai vazal.

Sepeninggal Katarabumi, Khairun yang pura-pura bersahabat dengan Portugi tetap melancarkan serangan terhadap penduduk Katolik di kerajaan Moro. Untuk itu Khairun dianggap sebagai musuh Portugis dan harus dilenyapkan. Pada masa pemerintahan gubernur De Mesquita Khairun berhasil dibunuh pada tahun $1570 \mathrm{~d}$ Benteng Gamlamo. Peristiwa ini merupaka titik balik penyebaran Katolik di Maluku Utara. Setelah naik takhta Babullah memula babak baru hubungan Portugis-Ternate yang berdampak langsung pada kelangsungan orang-orang Katolik di Moro. Ia memutuska semua hubungan baik yang selama in dijalin Khairun dengan Portugis termasuk menghentikan semua kemudahan atas mis penyebaran Katolik yang selama ini tela diberikan. Perubahan sikap Ternate in jelas terlihat dari ketiadaan dokumen resmi maupun surat menyurat a dan Portugis pada masa Babullah berkuasa (Abdurrachman, 2008:239)

Pada 1570 Babullah memula penyerangan terhadap kerajaan Moro. Dar wilayah Galela pasukannya kemudian menyisir sepanjang pantai utara dan selatan wilayah Halmahera Utara. Perlawanan paling sengit diberikan Portugis saat Ternate bermaksud untuk menguasai daerah Tolo. Akibat penyerangan tersebut penyebaran Katolik di Kerajaan Moro praktis terhenti. Pada akhir 1570 hanya tinggal dua orang pastor di kawasan ini, sementara tentara Portugis hanya tersisa 50 orang. Sisanya sudah kembali ke Ternate karena situasi sangat berbahaya. Orang katolik dari Moro yang mengungsi ke Ternate saat penyerangan tahun 1571 diberikan dua pilihan oleh Babullah; kembali ke islam atau tetap dengan Katolik dan menjadi tawanan. Mayoritas pribumi Katolik akhirnya memutuskan untuk kembali ke Islam dan akhirnya dipulangkan ke daerah asalnya.

Setelah Spanyol menguasai Ternate penyebaran Katolik kembali dilakukan di Moro namun dalam jumlah yang sedikit. Tahun 1606 ditandai dengan satu kunjungan pastor ke wilayah ini. Setahun kemudian lima pastor sudah dapat bertugas di empa desa namun konversi masyarakat terhamba disebabkan oleh pastor yang sakit. Penyebaran Katolik berakhir di wilayah Kerajaan Moro saat gubernur Spanyol terakhir di kawasan Maluku Utara yaitu Jeronimo da Silva menarik pasukan pada 1613. Penarikan pasukan secara besar-besaran diadakan dalam rangka melindungi pusat pemerintahan Spanyol di Manila yang menurut isu pada saa itu akan diserang oleh bajak laut dari Taiwan.

b. Penyebaran Katolik di Bacan

Layaknya Moro, penyebaran Katolik di wilayah Kerajaan Bacan berawal dar dibaptisnya raja mereka. Portugis masuk ke Bacan pada 1520 namun kegiatan penyebaran Katolik baru dilakukan 13 tahun sesudahnya. Saat mendarat di Bacan tahun 1533 keberadaan para pastor sangat ditentang oleh penguasa setempat. Baru pada 1557 penyebaran Katolik memperoleh kemudahan. Sultan Bacan menikah dengan anak perempuan Sultan Khairun tanpa persetujuan beliau. Saat melahirkan istri sultan meninggal dunia. Karena takut diserang oleh mertuanya-yang sesungguhnya tidak beralasan-Sultan Bacan bersedia untuk masuk Katolik agar kerajaannya dilindungi Portugis. Sultan Bacan kemudian diberi nama baptis Don Joao. Hal ini langsung diikuti dengan konversi oleh tujuh sangaji $i^{3}$ kesultanan dan seorang pangeran beserta keluarganya. Usai dikonversi menjadi Katolik Doan Joao dan Pastor Antonio Vaz melakukan penginjilan mengelilingi kerajaan tersebut dan mengkonversi banyak orang.

Berita konversi Sultan Bacan dan keluarganya membuat Sultan Khairun marah. Ia lalu meminta agar menantunya kembali ke Islam namun permintaan ini ditolak. Setelah Sultan Bacan Don Joao wafat adiknya Don Henrique memegang tampuk pemerintahan. Babullah yang saat itu berkuasa di Ternate pun sempat menghimbau agar Sultan Bacan kembali ke Islam namun saran ini tidak digubris. Babullah menyerang Bacan pertempuran itu. Don Henrique digantikan oleh Alauddin II dalam usia 18 tahun. Sama seperti pendahulunya raja baru ini sebenarnya tidak ingin tunduk pada Ternate. Hal ini terlihat saat ia mengatakan kepada seorang pastor yang berkunjung tahun 1581 di Bacan bahwa ia siap kembali ke Katolik asalkan Portugis mengirimkan sebuah armada yang kuat untuk melindungi Bacan dari serangan Ternate. Karena Portugis sedang mengalami kemerosotan ajakan Alauddin II tidak dipenuhi. Berbeda dengan Ternate yang sangat memusuhi Portugis, dari sini terlihat jelas bahwa Bacan dan juga Tidore justru ingin mengambil hati Portugis dengan cara apapun agar dapat mengimbangi kedigdayaan Ternate.

3 Gelar kepala komunitas tradisional atau kepala distrik (Amal, 2010a:487).
Babullah dalam rangka merangkul Bacan sekaligus memutuskan kerjasam kerajaan tersebut dengan Portugis, sempa menyerang ibukota Bacan yaitu Labuha dan mengembalikan gelar sultan kepad Raja Bacan. Sebelumnya sejak tahun 1560 Sultan Khairun dari Ternate merendahkan martabat Bacan dengan mengambil gelar sultan dari kerajaan Bacan dan menggantinya dengan sangaji. Saat menyerang Bacan Babullah menerapkan kebijakan yang sama saat pasukannya memusnahkan Katolik dari Moro. Setiap warga Katolik yang tidak bersedia kembali ke Islam harus mengungsi ke Benteng Gamlamo di Ternate dan menjadi tanggungan gubernur Portugis. Akhirnya para pribumi Katolik dari Bacan itu bersedi kembali ke Islam dan dipulangkan kembali ke daerah asal mereka.

Penyebaran agama Katolik di Labuha dilakukan sampai Belanda merampas benteng Portugis yang ada di Ambon dan Ternate pada 1605. Saat itu hanya tersisa dua orang pastor yang melayani daerah ini. Saat Spanyol menguasai Ternate empat tahun sesudahny konversi masyarakat ke agama Katolik mulai diadakan kembali dengan dikirimnya seorang pastor dari Ternate. Namun ketika Belanda menyerang benteng milik Spanyol di Bacan kegiatan misionaris juga berakhir di kerajaan itu. Hasil penyebaran katolik di Bacan memang tidak sebanyak yang dialami di Moro. Sampai 1562 tercatat hanya sebanyak 800 orang Bacan telah memeluk Katolik. Dibandingkan dengan Tidore dan Ternate, Bacan memang memiliki jumlah penduduk dan wilayah yang lebih sedikit. Ha ini pun yang menyebabkan Bacan kurang bisa menyaingi prestasi kedua kesultanan yang telah disebutkan diatas (Amal, 2010a: 205).

Begitu juga dengan di Moro, hambatan ain bagi penyebaran Katolik di Bacan acapkali datang dari para pastor. Faktor kelelahan dan ketidakcocokan dengan suhu dan makanan setempat membuat merekayang merupakan tulang punggung misiterkadang mengalami sakit serius sehingga harus digantikan. Belum lagi jika terbunuh 
seperti yang dialami Pastor Castro saat menggantikan Antonio Caz. Jumlah tenaga pastor yang terbatas pun menjadi kendal tersendiri. Umat Katolik di pulau-pulau kecil yang jauh dari ibukota Kerajaan Baca terkadang kembali ke agama asli karena tidak mendapat kunjungan rohaniwan dalam waktu yang lama (Amal, 2010a: 205).

c. Penyebaran Katolik di Ternate, Tidore dan Jailolo

Berbeda dengan Bacan dan Moro, penyebaran Katolik di Ternate, Tidore da Jailolo kepada rakyat jelata hampir tidak terjadi. Sebaliknya karena serangan dan tero kerajaan Ternate dan Tidore, kerajaan yang lebih inferior - seperti Moro dan Bacanjustru meminta bantuan kepada Portugis dengan segala cara. Salah satunya yaitu dengan mengijinkan para pastor menyebarkan ajaran Kristen di wilayah mereka. Pada masa itu Ternate dan Tidore adalah dua kerajaan terkuat di wilayah Maluku Utara sehingga tidak membutuhkan banyak bantuan dar Portugis. Sedangkan Jailolo sempat menjadi kekuasaan besar pada pertengahan abad 16 namun belakangan dianeksasi ke dalam wilayah Ternate. Satu-satunya penyebara Katolik di Jailolo yang berhasil dicatat adalah dikonversinya Kolano Sabia. Ia adalah seorang kemenakan Sultan Jailolo. Pada 155 Pastor De Beira sebenarnya diminta untuk membaptis Sultan Jailolo namun hal tersebut mendapat pertentangan sehingga tidak terlaksana. Petinggi kerajaan Ternate yan berhasil dikonversi menjadi Katolik adala Tabariji (Raja Ternate sebelum Khairun), ibu dan ayah tiri Tabariji, dan seorang keluarga sultan yang menggunakan nama baptis Donna Catarina. Selebihnya adalah budak perempuan yang menikah atau menjalankan pergundikan dengan orang Portugis ${ }^{4}$. Pada 4 Praktek pergundikan secara resmi memang tidak
dianjurkan oleh Agama Katolik dan Kerajaan Portugis. dianjurkan oleh Agama Katolik dan Kerajaan Portugis
Namun tetap saja banyak laki-laki Portugis hidup dalam
pergundikan atau menikah dengan penduduk lokal karena Kerajaan Portugis tidak mengijinkan wanita Portug untuk meninggalkan tanah airnya. Ada wanita Portugi yang dikirimkan dari panti asulan untuk nengatasi hal in berbanding 300 orng pria per tahun). Itupui (satu wanit

kasus Tabariji, ia dan keluarganya bersedia dikonversi ke Katolik agar menduduki takhta Kesultanan Ternate. Sebelumnya ia ditahan dan diasingkan ke Goa karena dianggap mendalangi penyerangan terhadap jemaat Katolik di Mamuya yang akhirnya membuat Raja Moro terbunuh.

Peristiwa besar yang menanda kemunduran Katolik di Ternate dan Maluku Utara secara keseluruhan adalah pembunuhan Sultan Ternate yaitu Khairun pada 1570 Putranya Babullah yang dilantik berikra untuk mengusir Portugis dari Maluku Utara. Langkah pertama yang dilakukan Babullah adalah memutuskan semua hubungan dengan Portugis. Babullah melarang semua orang di dalam wilayah Kesultanan Ternate untuk berpindah agama dari Islam ke Katolik. Babullah mulai mengepung Benteng Gamlamo pada tahun yang sama dan melarang pihak Portugis di dalam benteng untuk mengadakan kontak dengan orang luar kecuali hanya mencari makanan di siang hari. Pada saat yang sama pasukan Babullah menyerang kantong Katolik terbesar di Maluku Utara yaitu Moro dan Bacan. Kampung-kampung Katolik dimusnahkan dan yang berhasil kabur mengungsi ke benteng Portugis di Ternate. Keberadaan ribuan pengungsi ini tentu saja sangat menyusahkan Portugis. Kelaparan dan bantuan yang tak kunjung datang membuat Portugis akhirnya menyerah tanpa syara pada akhir tahun 1575. Aktifitas para pastor sebagai ujung tombak penyebaran agama Katolik di Maluku Utara sangat tergantung dari hubungan Portugis dengan penguasa setempat. Saat Babullah memblokade benteng dan kekuasaan Portugis menjadi lemah maka praktis penyebaran Katolik di wilayah in terhenti. Pada periode pengepungan Benteng Gamlamo (1570-1575) konversi penduduk

dapat dinikahi oleh pegawai rendahan Portun wanita yang Utara dan Ambon. Satu hal yang perlu dicatat disini adalah bahwa untuk mendukung perdagangan, kerajaan Portugis justru menganjurkan para abdi-nya untuk menetap di pusatpusat aktivitas mereka di luar tanah air dan menikah dengapenduduk lokal. Kerajaan Portugis beranggapan bahw dagang dengan orang yang sudah lama menetap di daerah ke Katolik di seluruh Maluku Utara praktis terhenti. Dengan berat hati Portugis akhirnya meninggalkan Ternate pada 1575 dan Benteng Gamlamo dijadikan pusat pemerintahan oleh sultan.

Kegiatan misi mulai berjalan kembali setelah Sultan Tidore mencoba merangkul Portugis dengan mengijinkan mereka membangun sebuah benteng di Tidore pada 1578. Saat itu baru para pastor diijinkan untuk menyebarkan Katolik di wilayah Tidore secara terbuka. Namun hal ini sangat ditentang oleh para pembesar kerajaan lainnya sehingga dapat dikatakan bahwa konversi rakyat biasa hampir tidak terjadi. Sebelum tahun 1578 meskipun sultan melarang penyebaran Katolik di wilayahnya, kaum rohaniwan Katolik sebenarnya sudah berhasil mendekati para bangsawan Tidore. Salah satunya adalah dengan mengkonversi salah seorang sepupu sultan Tidore yang mengepalai enam kampung di wilayah kesultanan Tidore pada tahun 1562. Hal ini mendapat pertentangan dari para pemuka Islam sehingga pada 1665 ketika seorang pangeran lain ingin dikonversi menjadi Katolik pembaptisannya dilakukan di Manila.

Menurunnya Penyebaran Katolik di Maluku Utara

Kemerosotan Portugis di Maluku Utara juga merupakan kemerosotan Katolik. Pertama adalah sejak Babullah mengusir Portugis dari Ternate. Kedua, dimulai sejak tahun 1580 dimana Portugis dan Spanyol yang merupakan musuh bebuyutan bersatu dibawah pemerintahan Raja Phillip II, yang berasal dari Spanyol. Salah satu kebijakannya adalah menutup semua pelabuhan Portugis dan mengalihkannya ke pelabuhan milik Spanyol. mengalihkannya ke pelabuhan milik Spanyol. Keadaan ini sangat menguntungkan rempah-rempah di Maluku. Inggris yang datang pada 1579 dan Belanda pada 1598 diterima dengan baik oleh Babullah karena bahwa keberadaan dua bangsa ini dapat memutus ketergantungan perdagangan cengkeh dengan pihak Portugis. Hubungan Belanda yang semakin intens dengan Ternate dan penyerangan terhadap enteng Portugis di Ambon oleh Belanda Manila, menyerang Gamlamo pada 1606 Baru sejak saat itu konversi pribumi ternate menjadi Katolik dapat dilakukan secar terang-terangan. Namun tetap saja tidak sebesar masa-masa sebelumnya.

Saat itu Spanyol mengadakan perjanjian dengan Ternate yang berisi antara ain bahwa sultan tidak akan menghalangi pewartaan Katolik maupun kegiatan umat Katolik yang sudah terbentuk. Spanyol juga memberikan perhatian cukup besar terhadap penyebaran Katolik. Beberapa gereja di Ternate dan Bacan juga direstorasi sebelun gubernur Spanyol kembali ke Manila. Tindakan lain yaitu menggempur daerahdaerah kantong Katolik yang sudah ada saat pendudukan Portugis. Daerah-daerah yang digempur ini sebelumnya masuk dalam wilayah Kerajaan Moro namun pada akhir abad ke 16 wilayah ini sudah dianeksasi ke dalam wilayah Ternate. Karena takut akan gempuran serdadu Spanyol, perwakilan dari penduduk Tolo dan beberapa daerah di sekitarnya bahkan mengirim wakil mereka untuk menghadap perwakilan Spanyol dan berjanji akan secepatnya menganut Katolik dan meninggalkan Islam.

Sampai pertengahan abad 17 penyebaran Katolik berjalan tersendat sendat. Hasil konversi pun tidak sebanding dengan apa yang dicapai pada abad 16. Para pastor hanya dapat mengadakan kunjungan singkat ke daerah-daerah karena pergolakan yang terjadi akibat perang antara Ternate melawan Tidore diselingi konflik bersenjata antara Spanyol dan Belanda. Suasana semakin dipersulit karena gejolak politik di Eropa dengan dipisahkannya Uni Spanyol-Portugi yang telah bersatu selama 60 tahun (1580 1640). Dalam perjanjian pemisahan itu wilayah Maluku Utara resmi dikuasai oleh Spanyol dengan ibukota di Manila (Bohm dan Pangemanan, 2010:149). Delapan ahun kemudian ruang gerak misionaris semakin terbatas karena Spanyol dan Belanda menandatangani perjanjian yan isinya bahwa Spanyol mengakui kedaulatan 
Belanda atas sebagian wilayah Maluku Utara dan dikemudian hari tidak akan berusaha memperluas wilayah kekuasaannya di Maluku Utara. Misi Katolik di Ternate dan Tidore resmi berakhir pada tahun 1662 ketika pasukan Spanyol ditarik kembali ke Manila untuk mengantisipasi isu yang beredar bahwa Manila dalam waktu dekat akan diserang oleh bajak laut dari Taiwan. Umat katolik yang ditinggalkan di Maluku Utara perlahan-lahan punah dan kembali ke agama asli mereka atau Kristen Protestan yang disebarkan oleh Belanda.

\section{Metode Penyebaran Katolik di Maluku} Utara

Pada penyebaran Katolik di Maluku Utara para pastor tidak menekankan pada hal-hal yang bersifat doktrin/konseptua melainkan menarik perhatian masyarakat dengan hal-hal yang belum mereka alami sebelumnya Selain ajakn dari pemimpin sebelumnya. Sechin ajakan dari pemimpin reka it-hal sederhana seperti mengadakan ritual-ritual gerejani berupa penyalaan lilin atau penggunaan musik terbukti efektif untuk menjaring masyarakat agar bersedia dikonversi menjadi Katolik. Anak-ana dan remaja biasanya mendapat porsi lebih banyak dalam kunjungan para pastor di desadesa. Selain karena lebih mudah ditemui jika dibandingkan orang dewasa yang sibuk bekerja, mereka juga lebih mudah menyerap ajaran yang diberikan.

Saat Pastor Fransiskus Xaverius datang pada 1546 ia mulai memadukan musik lokal Maluku Utara dalam setiap kunjungan ke desa-desa. Hal ini dapat dilakukan dengan berkaca pada pengalamannya saat bertugas di Comorin (India Selatan). Sebelum ampai di Maluku Utara di Malaka i juga sempat menerjemahkan beberapa do wajib, ajaran agama Katolik, serta beberap teks khotbah ke dalam Bahasa Melayu di Malaka. Sangat disayangkan terjemahan in hilang tak berbekas. Dalam mengkristenkan orang-orang Xaverius mempunyai metode tersendiri. Setiap hari ia akan berjalan dari atu kampung dan membunyikan lonceng dengan keras sehingga banyak orang datang erkerumun. Setelah terkumpul banyak orang maka ia akan mengharuskan orang tersebut untuk men hapalkan doa-doa dibacakan.Kelak ia akan kembalike kampung itu untuk menguji seberapa jauh mpung dilajur dilanjutkan dengan membaptis orang yang ia us unan dalam sebuah ibadah. Setelah it ia akan memberikan layanan rohani seperti mengadakan pelajaran agama, menikahka pasangan, mendengarkan pengakuan dosa serta mendoakan orang sakit. Di setiap kampung dibangun sebuah salib berukuran besar agar senantiasa mengingatkan orang akan kepercayaan baru yang dimiliknya. Pada setiap kampung diusahakan terdapat guru agama lokal yang dididik agar sementar waktu dapat mengoantikan pastor yan berkeliling ke wilayah lain (Keuning, yan berkeliling ke wilayah lain (Keuning, Tanpa 2008: 214-215).

Saat pertama kali datang di Maluku Utara para pastor harus ditemani penterjemah saat mengunjungi perkampungan. Seiring dengan waktu para rohaniwan perlahan-lahan dapat berkomunikasi menggunakan Bahasa Melayu. Namun lama kelamaan seiring dengan popularitas mereka yang semakin menanjak Bahasa Portugis juga digunakan dalam penyebaran agama Katolik. Hubungan yang intens dengan bangsa pendatan membuat masyarakat Maluku Utara, terutam para peting para petinggi kerajaan, juga mulai dapa bericara dengan Basasan penguasaan terhadap bahasa Portugis terutam terjadi pada masa dimana para sultan sangat bersimpatik terhadap keberadaan Portugis Masa ini berhasil dicapai salah satunya berka jasa Gubernur Antonio Galvao (1537-1540). Salah satu gagasan Galvao yang membuat Katolik semakin menarik adala dibukanya sekolah bagi anak-anak pribumi. Kurikulum yang diajarkan meliputi pelajaran menulis, berhitung, Bahasa Latin, dan agama Katolik. Semuanya itu diajarkan dengan bahasa Portugis. Mula-mula hanya keluar para sultan dan pembesarnya saja yang para sum belakangan kesentan ini diberikamun belaka man kribumi semna anc yang lain juga didirikan di wilayah Ternate, Tidore, dan Bacan. Selain sekolah para pasto juga mendirikan pusat pelayanan kesehatan
Umumnya masyarakat sangat antusias dalam menanggapi penyebaran Katolik di Maluku Utara. Seorang lanjut usia percaya bahwa badannya terasa lebih seht melakukan melakukan pengakuan dosa. Di Tolo pernah dibritan Katolik meminum air yang sudah diberkati pastor karena menganggap air tersebut dapat menangkal segala macam penyakit. Hal yang sama juga terjadi di Bacan saat pembaptisan pada tahun 1557. Mereka percaya bahwa percikan air saat pertama kali dibaptis secara masal merupakan cara yang ampuh untuk menangkal racun. Salah satu alasan orang Bacan masuk Katolik karena mereka menganggap bahwa agama tersebut merupakan sarana yang efektif untuk mengusir suwanggi; salah satu mahkluk halus yang paing ditakuti karema dipercaya halus yang paling ditakut karena dipercaya capat Porth Portugis tidak pernah diganggu oleh suwanggi karena sudah lama menganut Katolik. Pernah dilaporkan ketika terjadi kemarau panjang di Sakita (Morotai), kepala desanya pergi ke gereja dan berdoa minta hujan dengan cara memukul-mukul dada, kemudian mengangkat sebuah piring berisi minyak kelapa yang biasa dijadikan lampu sembari berdoa kepada Tuhan untuk mendatangkan hujan. Setelah itu sang kepala desa memberitahukan kepada penduduk jika menghendaki hujan turun mak mereka harus menyumbangkan minyak mak 227-228). gereja (Amal, 2010a: 217-218,

\section{PENUTUP}

Penyebaran agama Katolik yang dilakukan Portugis dan Spanyol berbarengan dengan usaha untuk memonopoli rempahrempah secara keseluruhan berdampak buruk bagi eksistensi mereka di Maluku Utara. Portugis mengharapkan bahwa penyebaran Katolik akan mendukung monopoli cengkeh yang mereka terapkan di Maluku Utara. Namun kenyataannya penyebaran agama Katolik-dan sikap semena-mena gubernur dalam menjair dalam menjalin tubura sultan-merupakan beberapa alasan para penguasa-penguasa muslim itu untuk Rich Ricklef, 2008: 45). Penyebaran Islam dan kekuatan sultan-sultan di Maluku Utara bahkan semakin kokoh beberapa tahun sebelum Portugis hengkang dari Maluk Utara. Hal ini sejalan dengan pendapat Reid ang berangapan bahwa dampak keberadan Portugis di Asia Tenggara justru semakin Porm is di Asia Tenggara justu semakin lokal tersebut (Reid, 2011: 315).

Harus diakui bahwa agama Katolik alam konteks keberadaan Portugis da Spanyol di Maluku Utara bersifat sanga politis. Pemimpin dan pejabat kerajaan loka dengan mudah beralih menjadi Katolik dengan harapan diberikan kemudahan oleh Portugis dalam berbagai hal. Sebagai contoh Raja Bacan dan Moro bersedia untuk dikonvers menjadi Katolik agar diberikan perlindungan oleh Portugis untuk mengantisipasi serangan onsu (a) Tabariji li Goa ar dapat kembali menjadi Raja Terna Sur Kat kembali menjadi Raja Terne. Sultan Khairun pun berusaha untuk mengakomodasi penyebaran Katolik di Moro karena ingin mendapat simpati dari Portugis. Di lain pihak, dalih untuk membela uma Katolik yang tertindas diterapkan Portugis untuk menyerang beberapa daerah. Padaha tujuan sebenarnya adalah menyenangkan penguasa lokal tertentu dengan maksud untuk memperkokoh monopoli rempah-rempah. Tingkat penyebaran Katolik berbandin urus dengan keintiman hubungan Portugis dan Spanyol dengan sultan-sultan di wilayah Maluku Utara. Pada masa tenang di mana hubungan berlangsung baik, jumlah umat Katolik di satu wilayah dapat mencapai puluhan ribu orang. Namun saat hubungan ni buruk - seperti saat Babullah bertakhta di Ternate dan berusaha untuk mengusir Portugis - penyebaran Katolik praktis berhenti dan umat yang sudah ada kembali lagi memelu agama aslinya karena ketiadaan kunjungan pastor.

Dalam menyebarkan Agama Katolik para misionaris berusaha untuk menjangkau alam pemikiran masyarakat yang bersahaja sehingga dalam pengajaran dititikberatkan pada penguasaan doktrin Kristiani. Akibatnya, meskipun jumlah orang yang dikonversi banyak namun pemahaman secara mendalam tentang ajaran Katolik masih dangkal dan tentu saja dapat disalahartikan. Secara resmi agama Katolik punah sejak 
1662 saat Spanyol menarik pasukannya ke Manila. Dewasa ini umat Katolik yang ada di Maluku Utara adalah hasil karya misionaris oleh pemerintah Belanda yang dimulai pada tahun 1935.

$$
* * * * *
$$

\section{DAFTAR PUSTAKA}

Abdurrachman, Paramita R. 2008. In Search of Spices: Portuguese Settlements on Indonesia Shores". Dalam Abdurrachman R. Abdurrachman. 2008. Bunga Angin Portugis di Nusantara, Jejak-jejak Kebudayaan Portugis di Indonesia: 1-22. Jakarta: LIPI Press

Abdurrachman, Paramita R. 2008. "PeninggalanPeninggalan yang Berciri Portugis di Ambon". Dalam Paramita R. Abdurrachman. 2008. Bunga Angin Portugis di Nusantara, Jejak-jejak Kebudayaan Portugis di Indonesia: 114161. Jakarta: LIPI Press.

Abdurrachman, Paramita R. 2008."Maluku, Portugis, dan Spanyol, Hubungan Antara Kerajaan Maluku dengan Kerajaan Portugis dan Spanyol dalam abad XVI dan XVII Sebagaimana Tersirat dalam Surat-Surat dan Dokumen Resmi". Dalam Paramita R. Abdurrachman. 2008. Bunga Angin Portugis di Nusantara: Jejak-jejak Kebudayaan Portugis di Indonesia: 227270. Jakarta: LIPI Press

Alwi, Des. 2005. Sejarah Maluku: Banda Naira, Ternate, Tidore, dan Ambon. Jakarta: Dian Rakyat.

Amal, Adnan.M. 2010a. Kepulauan RempahRempah, Perjalanan Sejarah Maluku Utara 1250-1950. Jakarta: Gramedia.

Amal, Adnan.M. 2010b. Portugis dan Spanyol di Maluku. Jakarta: Komunitas Bambu.

Andaya, Leonard. Y. 1993. The World of Maluku: Eastern Indonesia in the Early Modern Period. Honolulu: University of Hawaii Press.

Aritonang, Jan. S. 2006. Sejarah Perjumpaan Kristen dan Islam di Indonesia. Jakarta: BPK Gunung Mulia.

Boelaars, Huub. 2009. Indonesianisasi, Dari Gereja Katolik di Indonesia Menjadi Gereja Katolik Indonesia. Yogyakarta: Kanisius

Böhm, C.J dan Frits Pangemanan. 2010. Sejarah Gereja Katolik Maluku Utara 1534-2009.
Yogyakarta: Kanisius

Djafaar, Irza Arnyta. 2006. Jejak Portugis di Maluku Utara. Yogyakarta: Ombak.

Keuning, J. Tanpa Tahun. Orang Ambon, Portugis, dan Belanda, Sejarah Ambon Sampai Akhir Abad ke-17 (Ambonezen, Portugezen En Nederlanders, Ambon's Geschiedenis Tot Het Einde Van Zeventiende Eeuw), terjemahan Frans Rijoly. Ambon: Tidak Diterbitkan. Tanpa Tahun

Leirissa R.Z, G.A. Ohorella, dan Djuariah Latuconsina. 1999. Sejarah Kebudayaan Maluku. Jakarta: CV. Ilham Bangun Perkasa.

Reid, Anthony. 2011. Asia Tenggara Dalam Kurun Niaga 1450-1680. Jilid 2: Jaringan Perdagangan Global (Southeast Asia in The Age of Commerce 1450-1680. Volume two: Expansion and Crisis), terjemahan R.Z. Leirissa dan P. Soemitro. Jakarta: Yayasan Pustaka Obor Indonesia.

Rijoly, Frans. 1977. Sejarah Ambon dan Maluku Selatan (De Geschiedenis Van Ambon En De Zuid Molukken), terjemahan Frans Rijoly. Ambon: Tidak Diterbitkan.Tanpa Tahun.

Ricklef, M.C. 2008. Sejarah Modern Indonesia 1200-2008 (A History of Modern Indonesia Since c. 1200), terjemahan Tim Penerjemah Serambi. Jakarta: Serambi

Turner, Jack. 2011. Sejarah Rempah, Dari Erotisme Sampai Imperialisme (Spice, The History of a Temptation), terjemahan Muhammad Yesa Aravena. Jakarta: Komunitas Bambu.

Van den end, TH. 2008. Harta Dalam Bejana: Sejarah Gereja Ringkas. Jakarta: BPK Gunung Mulia

Van den end, TH dan J. Weitjens. 2001. Ragi Carita 1: Sejarah Gereja di Indonesia. Jakarta: BPK Gunung Mulia.

www.bps.go.id.http://s p 2010 . bps.go.id/index.php/site/ tabel?tid=321\&wid=8200000000 (diakses tanggal 7 Juni 2012)

www.bps.go.id.http://sp2010.bps.go.id/index. $\mathrm{php} /$ site/tabel? search tabel=Penduduk + Menurut+Wilayah+dan+Agama+yang+ Dianut\&tid $=321 \&$ search-wilayah=Indon esia\& wid=0000000000\&lang=id (diakses tanggal 7 Juni 2012) 